\title{
Antioxidant intake, plasma antioxidants and oxidative stress in a randomized, controlled, parallel, Mediterranean dietary intervention study on patients with rheumatoid arthritis Linda Hagfors*1, Per Leanderson², Lars Sköldstam³ ${ }^{3}$ Jan Andersson ${ }^{3}$ and Gunnar Johansson ${ }^{1}$
}

Address: ${ }^{1}$ Department of Food and Nutrition, Umeå University, SE-901 87 Umeå, Sweden, ${ }^{2}$ Department of Molecular and Clinical Medicine, Division of Occupational and Environmental Medicine, Linköping University, Sweden and ${ }^{3}$ Department of Medicine, Lasarettet SE-621 84, Visby, Sweden

Email: Linda Hagfors* - linda.hagfors@kost.umu.se; Per Leanderson - per.leanderson@lio.se; Lars Sköldstam - lars.skoldstam@hsf.gotland.se; Jan Andersson - jan.andersson@lio.se; Gunnar Johansson - gunnar.johansson@kost.umu.se

* Corresponding author

Published: 30 July 2003

Nutrition Journal 2003, 2:5

This article is available from: http://www.nutritionj.com/content/2/I/5

(C) 2003 Hagfors et al; licensee BioMed Central Ltd. This is an Open Access article: verbatim copying and redistribution of this article are permitted in all media for any purpose, provided this notice is preserved along with the article's original URL.
Received: 21 May 2003

Accepted: 30 July 2003

\begin{abstract}
Background: Previously we have reported that patients with rheumatoid arthritis (RA) obtained a significant reduction in disease activity by adopting a Mediterranean-type diet. The present study was carried out to investigate the antioxidant intake, the plasma levels of antioxidants and a marker of oxidative stress (malondialdehyde) during the study presented earlier.
\end{abstract}

Methods: RA patients randomized to either a Mediterranean type diet (MD group; $n=26$ ) or a control diet ( $C D$ group; $n=25)$ were compared during a three month dietary intervention study. Their antioxidant intake was assessed by means of diet history interviews and their intake of antioxidant-rich foods by a self-administered questionnaire. The plasma levels of retinol, antioxidants ( $\alpha$ - and $\gamma$-tocopherol, $\beta$-carotene, lycopene, vitamin $C$ and uric acid) and urinary malondialdehyde (MDA), a marker for oxidative stress, were determined using high performance liquid chromatography. The Student's t-test for independent samples and paired samples were used to test differences between and within groups. For variables with skewed distributions MannWhitney U-test and Wilcoxon signed ranks test were performed. To evaluate associations between dietary intake of antioxidants, as well as between disease activity, MDA and antioxidants we used Pearson's product moment correlation or Spearman's rank correlation.

Results: The MD group had significantly higher intake frequencies of antioxidant-rich foods, and also higher intakes of vitamin $C(p=0.014)$, vitamin $E(p=0.007)$ and selenium $(p=0.004)$, and a lower intake of retinol $(p=0.049)$, compared to the $C D$ group. However, the difference between the groups regarding vitamin $C$ intake was not significant when under- and over-repoters were excluded ( $p=0.066$ ). There were no changes in urine MDA or in the plasma levels of antioxidants (after $\mathrm{p}$-lipid adjustments of the tocopherol results), from baseline to the end of the study. The levels of retinol, vitamin $C$ and uric acid were negatively correlated to disease activity variables. No correlation was found between antioxidant intake and the plasma levels of antioxidants.

Conclusions: Despite an increase in reported consumption of antioxidant-rich foods during the Mediterranean diet intervention, the levels of plasma antioxidants and urine MDA did not change. 


\section{Background}

In a recent study we have shown that patients with rheumatoid arthritis (RA) that adopted a Cretan Mediterranean diet obtained a reduction in inflammatory activity, an increase in physical function and in vitality, whereas no significant changes were seen in the control group, who followed their habitual diet [1].

For a long time the beneficial effects of the Mediterranean diet have primarily been attributed to its lipid profile. However, recently attention has been drawn to the antioxidants [2-5]. Vegetables, fruit and olive oil have a central position in the Mediterranean diet and these food items contain a variety of compounds with an antioxidant capacity, such as vitamin $\mathrm{C}$ and E, carotenoids and polyphenols [2].

There is evidence indicating that a low antioxidant status is associated with a higher risk of developing RA [6-8]. Furthermore, the rheumatoid inflammation is associated with an increased generation of oxidants (reactive oxygen and nitrogen species), which play an important role in the inflammatory process and contribute to tissue destruction [9]. Antioxidant defences limit the damages caused by oxidants, such as those formed during inflammation. In addition, in vitro-studies and animal studies have shown that antioxidants also possess anti-inflammatory properties [10-13]. This implies that antioxidative defence mechanisms are of particular importance for patients with RA and that the effects of antioxidative nutrients ought to be further investigated.

Most controlled studies investigating the therapeutic use of antioxidant supplementation have not shown any significant effects on RA symptoms (reviewed in [14]). In contrast to these studies, in a placebo-controlled trial, vitamin $\mathrm{E}$ was reported to have a mild, but significant, analgesic effect [15]. Since many of the antioxidant compounds interact in the body, supplementation with individual antioxidants may not be the best way to strengthen the antioxidant defence. In a small study by Helmy et al [16] supplementation with a combination of antioxidants, in addition to standard treatment, gave better results regarding clinical indices of RA compared to standard treatment alone. This indicates that supplementation with a combination of antioxidants, or a diet providing a cocktail of different antioxidants, may be more effective than supplementation with single nutrients. Therefore, the beneficial effect of the Cretan Mediterranean diet, which we recently tested on patients with RA [1] could, at least in part, be attributable to the high content of antioxidants in this diet. Since this needs to be investigated further, the aims of the present study were to examine our patients with respect to their antioxidant intake, their plasma level of antioxidants, and by means of a marker of oxidative stress (malondialdehyde).

\section{Methods}

\section{Patients and study design}

The study has been approved by the local ethical committee and the ethical principles of the Helsinki Declaration were followed.

56 patients with RA according to the 1987 ACR criteria [17] were included in the study. The patients were enrolled in groups of two to six persons, with new groups starting every third week from September 1998 to November 2000. After baseline measurements they were randomized to either a modified Cretan Mediterranean Diet (MD) group or a Control Diet (CD) group. The randomization was done by means of block randomization, stratified for sex. $26 \mathrm{MD}$ subjects (21 women and 5 men, mean age 58 years) and 25 CD subjects (20 women and 5 men, mean age 59 years) completed the study. At baseline the $\mathrm{MD}$ group had a significantly higher Body Mass Index (BMI) and a longer disease duration compared to the CD group ( $\mathrm{p}=0.024$ and 0.047 , respectively). Apart from this no differences were seen between the groups at the start of the study (for details see reference 1).

All the patients had well controlled, although active, RA (Disease Activity Score from 28 joints $>2.0$ ) and a disease duration of at least 2 years. The pharmacological treatment had to have been kept stable prior to inclusion, i.e. the Disease Modifying Anti-Rheumatic Drugs (DMARD) had to be unchanged for $\geq 3$ months, the corticosteroids for $\geq 4$ weeks, and Non-Steroidal Anti-Inflammatory Drugs (NSAID) for $\geq 10$ days. Furthermore, the daily dose of oral corticosteroids was not to exceed $12.5 \mathrm{mg} /$ day of Prednisolone. Patients who had other conditions that demanded active medical attention were not included in the trial. Vegetarians and patients already eating a Mediterranean-like diet were excluded. Throughout the experimental period the doses of DMARD and corticosteroids were kept constant. The individual dose of NSAID could be adjusted, but the doses had to be documented in the study protocol. Four violations to the protocol in the form of intra-articular injections with triamcinolone hexacetonide were reported. The injections were given to one MD 
patient and three $\mathrm{CD}$ patients (for details see reference 1). None of these patients were excluded.

If the subjects of the study used any dietary supplementation (e.g. fish oils, vitamins, minerals, etc.) prior to the study this was recorded. All such supplementation had to be kept unchanged during the study. During the first three weeks both groups took part in an outpatient rehabilitation program at the Kalmar Hospital Rheumatology Unit. This program runs from 9 a.m. to 5 p.m., Monday to Friday, and consists of patient education, strength and fitness training, along with individual physio- and occupational therapy. During these weeks (Monday to Friday) all the patients were served lunch and dinner (Cretan diet or the ordinary hospital food, according to the randomization) which were planned by the first author (LH) and managed by the hospital food service establishment.

For the following nine weeks the MD group continued to eat the Mediterranean diet, while the $\mathrm{CD}$ group ate their normal diet, now preparing all meals themselves.

\section{Diets}

The Cretan Mediterranean diet has previously been tested by de Lorgeril et al, in a secondary prevention trial of coronary heart disease [18]. In the present study we based the experimental diet on the diet used in that study, but with some modifications in order to suit Swedish food habits. In brief, the instructions to our MD group were to eat a large amount of fruits, vegetables, pulses, cereals, fish (particularly fish with a high content of $\omega-3$ fatty acids) and nuts and seeds with a high content of $\alpha$-linolenic acid. The intake of meat (such as pork, beef, lamb or mutton), cured meat, sausage etc. were to be replaced by poultry, fish or vegetarian dishes. Both olive oil and canola oil were used for food preparations, baking and in salad dressings. The MD group were also advised to use two types of margarines based on canola oil: a liquid margarine ( $80 \%$ fat) for cooking and a half-fat margarine $(40 \%$ fat) to use on bread. Furthermore, the MD group were advised to replace high fat dairy products with low fat products. The traditional Mediterranean diet is generally characterised by a moderate and regular alcohol consumption, especially in the form of red wine. However, in the present study no recommendations were given regarding alcohol consumption. To compensate for the antioxidants in wine, we advised the MD group to drink green or black tea.

To promote good compliance to the Mediterranean diet some food items were supplied free to the MD group, namely: frozen vegetables, tea, olive oil, canola oil and the liquid and half-fat margarines based on canola oil.
During the three-week ORP, the MD group had six lessons from a dietician about Mediterranean food and cooking. They were also given written instructions and recipes to facilitate the preparation of meals at home. After the ORP the dietician was available weekly for telephone consultation, and every third week the MD group had the opportunity to meet the dietician and the other MD subjects.

\section{Dietary assessments}

At baseline and at week three and twelve, patients of both groups completed a self-administrated questionnaire. The questionnaire was specifically designed to investigate compliance with the Mediterranean diet and included 86 questions (both open and closed questions) mainly concerning food choices, food intolerance and dietary supplementation. Some questions were about food frequencies, where the subjects should state their average intake of various food items by marking one of six alternatives ranging from "rarely or never" to "two or more times per day". To be able to compare the consumption between the two groups, as well as consumption at different points in time, the food frequencies were converted to average consumption per month. For example, if a consumption of 3-5 times per week was marked this would be converted to 16 times per month.

To obtain more detailed data on the energy and nutrient intake, diet history interviews were conducted with 34 patients from both the experimental group and the control group ( 15 women and 2 men from each group). The only selection criterion for taking part in the diet history interviews was that the subjects were included in the study on February the $15^{\text {th }} 1999$, or later. One purpose of the diet history interviews was to study the compliance with the experimental and control diets when the patients were preparing their meals at home. Therefore, all the interviews were performed between study weeks seven and twelve. It covered the intake during the past month but never included the ORP. The interview started with questions about the subject's meal patterns on weekdays and weekends. Subsequently each meal and between-meal snack was discussed in detail, with questions about food choices, frequencies and portion sizes. To estimate the average portion sizes, household measurements, validated food portion photographs [19], bags of rice of different sizes or standard weights of food items [20] were used. Most of the interviews were performed by the first author (LH) but two other specially trained dieticians interviewed five patients each. The interviews were either conducted in the subject's home or at the rheumatology unit, Kalmar Hospital.

The estimated intake of energy and nutrients, assessed by the diet history method, were calculated using the nutritional analysis package MATs 4_03e. This program is 
based on the Swedish National Food Administration's food composition database, PC-kost (version 2_97). For composite food items and supplements not listed in the database the nutrient content was entered manually. When uncooked foods were used in cooked dishes the amount of ascorbic acid was adjusted by the program, i.e. the ascorbic acid was decreased to $50 \%$ of the original value.

The energy and nutrient intake was calculated both including and excluding dietary supplements.

\section{Validation of the diet history interviews}

To obtain a crude estimate of the validity of the diet history interviews, we compared the reported energy intake with the energy expenditure of the subjects. The energy expenditure was estimated using a three-day activity registration method, previously used in the SOS (Swedish Obese Subjects) study [21]. If a person is in energy balance the habitual energy intake (EI) should equal the energy expenditure (EE). In the present study, subjects with a ratio EI:EE between 0.79 and 1.21 were regarded as valid reporters, those with a ratio less than 0.79 were regarded as under-reporters and those with a ratio greater than 1.21 as over-reporters [22].

The diet history interviews were also validated by comparing the reported energy intake with the energy expenditure determined by the doubly labelled water method (performed for 9 subjects), and the excretion of nitrogen, sodium and potassium in 24-h urine samples, were used to validate the reported intake of protein, sodium and potassium. The results of the validation with biological markers will be presented elsewhere.

\section{Assessment of plasma antioxidants and urine malondialdehyde \\ Blood and urine collection}

Blood samples were drawn into heparinazed vacutainer tubes between 8.00 and 9.00 a.m., after an overnight fast. When the blood had reached room temperature the samples were centrifuged at 2,000 rpm for 10 minutes and aliquots of plasma were transferred to $1.5 \mathrm{ml}$ Eppendorf tubes and stored at $-70^{\circ} \mathrm{C}$ before being analyzed. For analysis of vitamin C, $500 \mu \mathrm{l}$ plasma was immediately transferred to Eppendorf tubes and mixed with an equal volume of $10 \% \mathrm{~m}$-phosphoric acid before the samples were frozen.

After receiving instructions, each participant collected a morning urine sample $(15 \mathrm{ml})$ on the day of the visit to the hospital. On arrival the urine samples were frozen at $20^{\circ} \mathrm{C}$.

\section{Chemicals}

1,1,3,3-tetraethoxypropane (97\%), $\beta$-carotene (95\%), lycopene (95\%), vitamin A, $\alpha$-tocopherol, $\gamma$-tocopherol, Lascorbic acid (>99\%), uric acid (>99\%) and butylated hydroxytoluene (BHT) were all from Sigma Chemical Company St. Louis IN, USA. The thiobarbituric acid (99\%) was from Merck KGaA, Darmastadt, Germany.

The standard reference material $968 \mathrm{~b}$ (for carotenoids and tocopherols) was obtained from the National Institute of Standards and Technology, Gaithersburg, MD, USA.

\section{Biochemical analysis \\ Malondialdehyde}

The urine was thawed, vortexed and centrifuged at 2,000 rpm for 5 minutes. After determining the specific density, aliquots of $50 \mu \mathrm{l}$ urine were mixed with $300 \mu \mathrm{l}$ o-phosphorus acid $(0.5 \mathrm{~mol} / \mathrm{L})$ and $150 \mu \mathrm{l}$ thiobarbituric acid $(23 \mathrm{mmol} / \mathrm{L})$ in $1.5 \mathrm{ml}$ Eppendorf tubes. After this, the samples were incubated for 55 minutes at $95^{\circ} \mathrm{C}$ and then chilled on ice before they were centrifuged for 3 minutes at $14,000 \mathrm{~g}$. Malondialdehyde (MDA) was then determined using HPLC (high performance liquid chromatography) and $20 \mu \mathrm{l}$ of each sample was injected and separated on a Chromolite Performance column (100 x $4.6 \mathrm{~mm}, \mathrm{RP}-18 \mathrm{e}$, Merck KGaA, Darmastadt, Germany). The mobile phase consisted of $70 \% 50 \mathrm{mmol} / \mathrm{L}$ potassium phosphate (pH 6.8) and $30 \%$ methanol and the flow rate was $3 \mathrm{ml} / \mathrm{min}$. The malondialdehyde - thiobarbituric acid complex was detected with a fluorescence detector (Merck-Hitatchi F 1000 Fluorescence Spectrophotometer) with excitation and emission wavelengths of 525 and $550 \mathrm{~nm}$, respectively. The density-corrected malondialdehyde concentrations (adjusted MDA) were calculated by using the following formula: Density corrected value $=$ concentration in urine $\times((1.024-1) /($ concentration in urine -1)). Standard curves of malondialdehyde were prepared from 1,1,3,3-tetraethoxypropane $(1-5 \mu \mathrm{mol} / \mathrm{L})$ mixed with o-phosphorous acid and thiobarbituric acid and treated in the same way as the samples.

\section{Vitamin $A$ and fat and water soluble antioxidants}

Vitamin A, $\alpha$ - and $\gamma$-tocopherol and carotenoids, was determined using HPLC according to a method that has been described previously by Hess et al [23]. The quantification of the single compounds was performed by an external standard method based on peak area. The concentrations of the different samples were also checked and compared with the standard reference materials $968 \mathrm{~b}$ from the National Institute of Standards and Technology, USA (carotenoids and vitamin E) and INSTAND e.V. Düsseldorf, Germany (vitamin A and E). 
Table I: Comparison of reported food consumption frequencies (servings per month) between the Mediterranean Diet (MD) group and the Control Diet (CD) group. The food consumption frequencies are based on the food frequency questionnaires. The data are presented as medians (25th-75th percentiles).

\begin{tabular}{|c|c|c|c|c|c|c|c|}
\hline & \multicolumn{3}{|c|}{ MD group $(n=26)$} & \multicolumn{3}{|c|}{$C D$ group $(n=25)$} & \multirow[t]{3}{*}{ p-value* } \\
\hline & \multicolumn{3}{|c|}{ Time (weeks after dietary shift) } & \multicolumn{3}{|c|}{ Time (weeks after start of study) } & \\
\hline & 0 & 3 & 12 & 0 & 3 & 12 & \\
\hline $\begin{array}{l}\text { Cooked root } \\
\text { vegetables }\end{array}$ & $6(2-16)$ & $16(6-16)$ & $I I(5-16)$ & $2(2-6)$ & $6(0-6)$ & $2(0-6)$ & 0.027 \\
\hline $\begin{array}{l}\text { Raw root } \\
\text { vegetables }\end{array}$ & $6(2-16)$ & $16(16-26)$ & $6(6-16)^{\dagger}$ & $6(1-16)$ & $6(2-6)$ & $6(2-16)$ & 0.013 \\
\hline $\begin{array}{l}\text { Cooked green } \\
\text { vegetables }\end{array}$ & $16(6-16)$ & $16(16-26)$ & $26(16-26)^{\ddagger}$ & $6(4-16)$ & $6(4-16)$ & $6(2-16)$ & $<0.001$ \\
\hline $\begin{array}{l}\text { Raw green } \\
\text { vegetables }\end{array}$ & $16(6-19)$ & $26(24-37)$ & $21(16-26)^{\ddagger}$ & $16(6-26)$ & $16(6-26)$ & $6(4-21)$ & 0.001 \\
\hline Legumes & $2(0-6)$ & $11(5-16)$ & $6(2-16)^{\S}$ & $2(0-4)$ & $2(2-6)$ & $2(0-2)$ & 0.002 \\
\hline Fruit and berries & $16(6-26)$ & $16(14-26)$ & $16(6-26)$ & $16(4-48)$ & $16(2-26)$ & $6(2-21)^{\dagger}$ & 0.395 \\
\hline Fish & $6(6-6)$ & $16(6-16)$ & $16(16-16)^{\S}$ & $6(2-6)$ & $6(6-16)$ & $6(2-6)$ & $<0.001$ \\
\hline Shellfish & $2(0-2)$ & $2(0-6)$ & $4(2-6)^{\ddagger}$ & $2(0-2)$ & $2(0-2)$ & $2(0-2)$ & $<0.001$ \\
\hline Black tea & $7(0-16)$ & $7(0-42)$ & $7(0-42)$ & $7(0-42)$ & $7(0-42)$ & $7(0-42)$ & 0.015 \\
\hline Green tea & 0 & $25(0-42)$ & $7(0-42)^{\S}$ & 0 & 0 & 0 & $<0.001$ \\
\hline
\end{tabular}

*The $\mathrm{p}$-values refer to differences between the MD and CD groups concerning the change from baseline to week I2. Differences between the groups were analysed by Mann-Whitney $U$ test. Statistically significant change from baseline to week $I 2$ : $\dagger P<0.05, \ddagger P<0.0 I, \S P<0.00 I$. Withingroup differences at week 12 compared to baseline were evaluated by Wilcoxon signed ranks test.

Table 2: Comparison of reported dietary intake (excluding supplements) between the Mediterranean Diet (MD) group and the Control Diet (CD) group. The reported dietary intake is based on the diet histories performed between study weeks seven and twelve. The data are presented as mean values \pm SD.

\begin{tabular}{lccc}
\hline & MD group $(\mathrm{n}=17)$ & CD group $(\mathrm{n}=17)$ & P-value* \\
\hline Vitamin A (RE†) & $1560 \pm 770$ & $1760 \pm 930$ & 0.500 \\
Retinol $(\mu \mathrm{g})$ & $672 \pm 325$ & $1115 \pm 760$ & 0.049 \\
$\beta$-carotene $(\mu \mathrm{g})$ & $5000 \pm 4190$ & $3550 \pm 2620$ & 0.339 \\
Vitamin $\left(\alpha-\mathrm{TE}^{\ddagger}\right)$ & $13 \pm 4$ & $9 \pm 4$ & 0.007 \\
$\alpha$-tocopherol $(\mathrm{mg})$ & $12 \pm 3$ & $9 \pm 3$ & 0.007 \\
Vitamin C $(\mathrm{mg})$ & $157 \pm 78$ & $106 \pm 76$ & 0.014 \\
Selenium $(\mu \mathrm{g})$ & $56 \pm 17$ & $39 \pm 15$ & 0.004 \\
\hline
\end{tabular}

*P-values refer to the difference between the MD and CD groups. Differences between groups were analysed by the Students t-test for independent samples, except for retinol, $\beta$-carotene and vitamin $C$ which were evaluated by the Mann-Whitney $U$ test. †retinol equivalents. $\ddagger \alpha-$ tocopherol equivalents

Analyses of vitamin $\mathrm{C}$ and uric acid were also performed using HPLC. The samples (diluted 1:1 with 10\% m-phosphorous acid) were thawed at $4{ }^{\circ} \mathrm{C}$ and centrifuged at $14,000 \mathrm{~g}$ for 2 minutes and $20 \mu \mathrm{l}$ aliquots of the clear supernatants were injected in the chromatograph. Both vitamin $\mathrm{C}$ and uric acid were determined with a spectrophotometric detector at the wavelength $262 \mathrm{~nm}$. The HPLC pump was a 880-PU and the detector a $875-\mathrm{UV}$, both from Jasco (Japan Spectroscopic Company Ltd., Tokyo, Japan) and the injector was a Rheodyne 7125 from Rheodyne Inc., Cotati, CA, USA. The analytical column was a Chromolite Performance column $(100 \times 4.6 \mathrm{~mm}$, RP-18e, Merck KGaA, Darmastadt, Germany). The mobile phase consisted of $200 \mathrm{mmol} / \mathrm{L} \mathrm{KH}_{2} \mathrm{PO}_{4}, \mathrm{pH} 3.0$ and the flow rate was $2.5 \mathrm{ml} /$ minute. Standard curves with a concentration of $0-100 \mu \mathrm{mol} / \mathrm{L}$ (vitamin C) and $0-300$ $\mu \mathrm{mol} / \mathrm{L}$ (uric acid) were prepared and used for the quantification. Stock solutions with a concentration of 10 $\mathrm{mmol} / \mathrm{L}$ were first prepared in water (vitamin C) or 0.05 $\mathrm{mol} / \mathrm{L} \mathrm{NaOH}$ (uric acid) and then diluted further with $5 \%$ m-phosphorus acid.

\section{Clinical and laboratory assessments}

Clinical and laboratory evaluations were performed at baseline and in week three, six and twelve, and comprised Disease Activity Score from 28 joints (DAS28; a clinical assessment of disease activity), the Health Assessment Questionnaire (HAQ; a self-administered questionnaire 
used to assess functional capacity for activities of daily living), the Westergren Erythrocyte Sedimentation Rate (ESR), and the C-reactive protein (CRP) and thrombocyte count.

\section{Statistical methods}

The Student's t-test for independent samples was used to test differences between groups regarding plasma levels of antioxidants, urine MDA and nutrient intake. For these variables within-group differences from baseline to week 12 were evaluated using Student's t-test for paired samples. For variables with skewed distributions (plasma $\beta$ carotene and intakes (including supplements) of retinol, $\beta$-carotene, $\alpha$-tocopherol, total vitamin $\mathrm{E}$ and ascorbic acid, as well as retinol, $\beta$-carotene and vitamin $C$ intake when supplements were excluded), and for reported consumption of food items, the Mann-Whitney U-test was performed to test differences between the groups. For these variables the Wilcoxon signed ranks test was used to analyze differences within groups, from baseline to week 12.

To evaluate the association between dietary intake and the plasma levels of antioxidants, as well as between disease activity, MDA and plasma antioxidants, we used Pearson's product moment correlation. However, Spearman's rank correlation was used for variables with skewed distributions (plasma $\beta$-carotene, CRP and intakes of $\beta$-carotene, $\alpha$-tocopherol, total vitamin $\mathrm{E}$ and ascorbic acid, when supplements were included).

When associations between plasma antioxidants and variables related to disease activity were evaluated, we used the baseline levels of all the study subjects. When relations between dietary intake of antioxidants and plasma levels of antioxidants were evaluated, we used the reported nutrient intake obtained from the diet history interviews and the mean plasma levels of antioxidants taken in the same time period, i.e. between weeks 6 and 12 .

The statistical analyses were performed using SPSS for Windows, version 11.0.1. A P value of $<0.05$ was considered statistically significant.

\section{Results}

\section{Dietary intake}

At baseline there were no significant differences between the groups regarding consumption frequencies of food items rich in antioxidants (table 1).

The main increases in several antioxidant-rich food items were seen during the ORP (week three), when lunch and dinner were served at the Rheumatology unit (table 1). At the end of the study, the intake frequencies of both raw and cooked vegetables, legumes, fish, shellfish and green tea, had increased in the MD group. In the control group there was a significant decrease in the reported intake frequency of fruit and berries. When comparing the two groups the changes in food consumption frequencies of almost all the food items studied, were significantly greater in the MD group.

The nutrient intake during the second half of the study was estimated by means of the diet history interviews. Since the results at the group level were unchanged, whether we excluded under- and over-reporters or not (with the exception that there was no significant difference between the groups regarding vitamin $\mathrm{C}$ intake, when under- and over-reporters were excluded, $\mathrm{p}=$ 0.066 ), the results of all the diet history interviews are presented (table 2). When comparing the nutrient intakes (excluding supplements), the MD group had a lower reported intake of retinol and a higher intakes of vitamin $\mathrm{C}$, $\alpha$-tocopherol, total vitamin $\mathrm{E}$ and selenium, compared to the $\mathrm{CD}$ group.

When supplements were included in the nutrient intake, there was no difference between groups regarding intake of retinol ( $p=0.099)$. The intakes of vitamin $\mathrm{C}, \alpha$-tocopherol, total vitamin $\mathrm{E}$, and selenium was still higher in the MD group with this approach $(\mathrm{p}=0.034, \mathrm{p}=0.003, \mathrm{p}$ $=0.004$ and $\mathrm{p}=0.021$ respectively) .

In comparison with the Average Requirement (AR), according to the Nordic Nutrition Recommendations (NNR) [24], the intake (excluding supplements) of all the MD subjects exceeded the AR for vitamins $A$ and $C$ and selenium. No AR for vitamin $\mathrm{E}$ has been stated in the $\mathrm{NNR}$, but in the MD group the vitamin $\mathrm{E}$ intake of all the subjects exceeded the recommended intake (NNR) $[24,25]$. In the $C D$ group, our data indicates that a number of patients did not reach the AR, namely one in the case of vitamin $\mathrm{A}$, one regarding vitamin $\mathrm{C}$ and six regarding selenium. Eight $\mathrm{CD}$ subjects did not reach the recommended intake of vitamin E. Of these eight subjects one had an intake of vitamin $\mathrm{E}$ that was below the lower limit of intake according to the NNR. However, when under-reporters (two CD subjects) were excluded, all the CD subjects reached the AR for vitamins A and C. Only six control subjects had a vitamin $\mathrm{E}$ intake below the recommended intake (and none under the lower limit of intake) and four $\mathrm{CD}$ subjects still had a selenium intake below the AR. The number of subjects that exceeded the AR and recommended intake did not change when we included the dietary supplements in the nutrient intake.

\section{Levels of plasma antioxidants and urine malondialdehyde}

No differences were seen between the groups regarding plasma levels of antioxidants or the marker of oxidative stress, MDA in urine, at the start of the study (table 3). 
Table 3: Comparison of plasma levels of retinol ( $\mathrm{mmol} / \mathrm{l})$, antioxidants $(\mathrm{mmol} / \mathrm{l})$ and urine malondialdehyde $(\mathrm{mmol} / \mathrm{l})$ between the Mediterranean Diet (MD) group and the Control Diet (CD) group. The data are presented as mean values \pm SD.

\begin{tabular}{|c|c|c|c|c|c|c|}
\hline & \multicolumn{3}{|c|}{ MD group $(n=26)^{*}$} & \multicolumn{3}{|c|}{$C D$ group $(n=25)^{\dagger}$} \\
\hline & \multicolumn{3}{|c|}{ Time (weeks after dietary shift) } & \multicolumn{3}{|c|}{ Time (weeks after start of study) } \\
\hline & 0 & 3 & 12 & 0 & 3 & 12 \\
\hline Retinol & $2.32 \pm 1.07$ & $2.21 \pm 0.70$ & $2.12 \pm 0.63$ & $2.17 \pm 1.15$ & $2.23 \pm 0.98$ & $2.01 \pm 0.62$ \\
\hline$\beta$-carotene & $0.56 \pm 1.20$ & $0.72 \pm 1.03$ & $0.49 \pm 0.85$ & $0.31 \pm 0.21$ & $0.43 \pm 0.28$ & $0.36 \pm 0.25$ \\
\hline Lycopene & $0.35 \pm 0.23$ & $0.39 \pm 0.25$ & $0.40 \pm 0.26$ & $0.27 \pm 1.17$ & $0.30 \pm 0.18$ & $0.26 \pm 0.15$ \\
\hline Vitamin C & $51 \pm 16$ & $62 \pm 16$ & $51 \pm 20$ & $54 \pm 22$ & $62 \pm 20$ & $52 \pm 28$ \\
\hline$\alpha$-tocopherol & $36 \pm 11$ & $33 \pm 8$ & $30 \pm 9 \|$ & $34 \pm 7$ & $32 \pm 8$ & $31 \pm 9$ \\
\hline$\alpha$-tocopherol:(C+TG) ratio $\ddagger$ & $4.94 \pm 1.13$ & $5.27 \pm 1.22$ & $4.51 \pm 1.27$ & $5.12 \pm 1.07$ & $4.93 \pm 1.23$ & $4.85 \pm 1.27$ \\
\hline$\gamma$-tocopherol & $2.42 \pm 1.15$ & $2.26 \pm 0.96$ & $1.85 \pm 0.83 \pi$ & $2.46 \pm 1.13$ & $1.96 \pm 0.63$ & $2.06 \pm 0.80$ \\
\hline$\gamma$-tocopherol:(C+TG) ratio $\ddagger$ & $0.32 \pm 0.15$ & $0.34 \pm 0.14$ & $0.26 \pm 0.11^{* *}$ & $0.37 \pm 0.16$ & $0.31 \pm 0.13$ & $0.32 \pm 0.12$ \\
\hline Uric acid & $293 \pm 68$ & $304 \pm 75$ & $297 \pm 83$ & $262 \pm 59$ & $261 \pm 57$ & $265 \pm 73$ \\
\hline Malondialdehyde & $1.23 \pm 0.52$ & $1.21 \pm 0.30$ & $1.07 \pm 0.34$ & $1.21 \pm 0.58$ & $1.36 \pm 0.58$ & $1.24 \pm 0.66$ \\
\hline Malondialdehyde adj.§ & $2.18 \pm 0.75$ & $2.51 \pm 0.64$ & $2.22 \pm 0.46$ & $2.09 \pm 0.46$ & $2.08 \pm 0.54$ & $2.15 \pm 0.78$ \\
\hline
\end{tabular}

*Complete data on plasma concentrations of vitamin $C$ and uric acid were only available for 25 diet group subjects. Complete data on plasma $\alpha$ tocopherol were available for 24 diet group subjects. †Complete data on plasma concentrations of lycopene were only available for 22 control group subjects. Complete data regarding the other antioxidants were available for 23 control subjects. $\ddagger \mathrm{C}=$ plasma total cholesterol, $\mathrm{TG}=$ plasma triglycerides, i.e. tocopherol:(cholesterol+triglycerides), $\mathrm{mmol} / \mathrm{l}: \mathrm{mmol} / \mathrm{l}$. §Malondialdehyde adjusted for density. Statistically significant change from

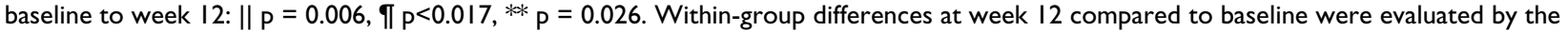
Student's t-test for paired-samples, except for $\beta$-carotene which was analysed by the Wilcoxon signed ranks test.

At the end of the study $\alpha$-tocopherol and $\gamma$-tocopherol were significantly below the baseline levels in the $\mathrm{MD}$ group. When tocopherols were expressed in relation to plasma lipids, by dividing $\alpha$ - and $\gamma$-tocopherol respectively with p-cholesterol plus p-triglycerides, the change from baseline to week 12 did not reach statistical significance regarding $\alpha$-tocopherol $(\mathrm{p}=0.076)$. However, the baseline level of $\alpha$-tocopherol was correlated to the plasma concentrations of both cholesterol $(r=0.402, p<$ $0.01)$ and triglycerides $(\mathrm{r}=0.591, \mathrm{p}<0.01)$, whereas the level of $\gamma$-tocopherol correlated only to plasma triglycerides $(\mathrm{r}=0.381, \mathrm{p}<0.01)$. Therefore we also calculated the $\gamma$-tocopherol:triglycerides ratio, and when $\gamma$-tocopherol was expressed in relation to p-triglycerides the changes from baseline did not reach statistical significance $(\mathrm{p}=$ 0.133).

When the dietary intake (including supplements) of nutrients (retinol, $\beta$-carotene, $\alpha$-tocopherol and ascorbic acid) was related to the plasma levels of the corresponding nutrients, no significant correlation was found. However, the plasma levels of some nutrients were associated with variables related to disease activity. Statistically significant inverse correlation was observed between retinol and ESR $(\mathrm{r}=-0.38, \mathrm{p}<0.01)$, DAS28 $(\mathrm{r}=-0.31, \mathrm{p}<0.05)$ and CRP $(\mathrm{r}=-0.48, \mathrm{p}<0.01)$ respectively. A negative relationship was also found between vitamin C and ESR $(r=-0.33$, p < $0.05)$ as well as between vitamin $\mathrm{C}$ and the HAQ score ( $\mathrm{r}$ $=-0.34, \mathrm{p}<0.05)$. Furthermore, uric acid was negatively correlated with the thrombocyte count $(\mathrm{r}=-0.28, \mathrm{p}<$ 0.05).

The concentration of MDA in urine did not change statistically in any of the groups during the study period. No correlation was found between MDA and the indices of disease activity. However, at baseline the concentrations of MDA in urine as well as the adjusted MDA, were inversely related to the plasma concentration of $\gamma$-tocopherol $(\mathrm{r}=-0.30, \mathrm{p}<0.05$ and $\mathrm{r}=-0.36, \mathrm{p}<0.05$ respectively).

\section{Discussion \\ Dietary Antioxidants}

In the present study we investigated the plasma levels and nutrient intake of antioxidants that are abundant in the traditional Mediterranean diet, i.e. carotenoids, vitamin $\mathrm{C}$, vitamin $\mathrm{E}$ and selenium [2]. After the intervention the consumption of several antioxidant-rich foods increased in the MD group, and as expected this group had a higher intake of most antioxidants compared to the CD group.

More surprising were the results for plasma antioxidants. Although the consumption of antioxidant-rich foods increased, the concentrations of plasma antioxidants were relatively constant throughout the study period. From baseline to the end of the study the plasma levels of $\alpha$ tocopherol and $\gamma$-tocopherol even decreased to significantly lower concentrations in the MD group. Since tocopherols circulate in the blood with the lipoproteins, the 
plasma levels are often influenced by the blood lipid concentration. During the course of this study, the total cholesterol decreased significantly in the MD group (results presented elsewhere) [1] and it is possible that this change caused the decreased levels of plasma tocopherols as well. For this reason we expressed the tocopherol levels as the ratio of tocopherol:(total cholesterol+triglycerides) as proposed by Turnham et al [26]. When the concentration of cholesterol and triglycerides was adjusted for, the changes in plasma $\alpha$-tocopherol did not reach statistical significance. Usually, the concentrations of tocopherols are expressed as tocopherol:total cholesterol or tocopherol:(total cholesterol+triglycerides), but since $\gamma$-tocopherol only correlated to triglycerides we also calculated the $\gamma$ tocopherol:triglycerides ratio. When $\gamma$-tocopherol was presented in relation to triglycerides this concentration was also unchanged.

Nevertheless, although the reported intake of vitamin $\mathrm{E}$ was higher in the MD group, the lipid adjusted plasma levels did not increase. One reason for this could be a decreased intake of fat, since the bio-availability of vitamin $\mathrm{E}$ is affected by the presence of fat. For the same reason the fat intake could also have affected the levels of $\beta$ carotene. According to the diet history interviews the MD group had a significantly lower intake of total fat compared to the CD group $(\mathrm{p}=0.005)$ (data not presented). However, the relation between the intake of fat and vitamin $\mathrm{E}$ in each meal must be investigated to clarify this. The intake of fat and biochemical markers of fat intake will be presented elsewhere.

The levels of tocopherols in the MD group may also have been affected by the increased intake of fish or other foods rich in polyunsaturated fatty acids (PUFA). These fatty acids are easily oxidized and may therefore increase the expenditure of vitamin E. Tulleken et al [27], compared two groups of RA patients receiving either supplementation with fish oil (rich in $\omega$-3 PUFA) plus $12.9 \mathrm{mg} \alpha$-tocopherol or coconut oil plus $10.3 \mathrm{mg}$ of $\alpha$-tocopherol daily. Although the coconut oil-treated group received slightly less $\alpha$-tocopherol, by the end of the study measures of vitamin E status were significantly higher in this group compared to the fish oil-treated group.

The influence of antioxidant-rich foods on the plasma concentration of antioxidants has been investigated in healthy subjects. Zino et al [28], showed that an increased intake of fruit and vegetables resulted in a raised plasma concentration of vitamin $\mathrm{C}, \alpha$-carotene and $\beta$-carotene. Interestingly, these changes were seen within the first two weeks of intervention, indicating that the plasma antioxidants in question respond quite fast to changes in dietary intake of antioxidants. In contrast, the levels of tocophe- rols may be more difficult to elevate by means of increasing the intake of vitamin E-rich foods [29].

In healthy individuals the plasma levels of antioxidants may be affected by many factors other than the nutrient intake, such as the degree of absorption, intake of other nutrients, homeostatic regulation etc. How the plasma antioxidants of RA patients are influenced by intervention with an antioxidant-rich diet has, to our knowledge, not been studied before. A possible explanation for the lack of correlation between dietary intake and plasma antioxidants, in the present investigation, is that the plasma levels of nutrients are mainly influenced by the inflammatory process, and to a lesser extent by the dietary intake. Several authors have reported depressed antioxidant levels in the plasma or serum of RA patients [30-36]. In addition, Honkanen et al [37] showed that in 50 RA patients, six parameters of disease activity explained $66 \%$ of the variation in serum zinc. They also reported that the low level of serum selenium found in RA patients was associated with joint score. We found that plasma retinol, ascorbic acid and uric acid were inversely related to indices of disease activity. In contrast to our results, in one study the level of serum vitamin A was shown not to be associated with blood parameters of inflammation or the joint score [35]. Only disease activity assessed by the physician was related to the level of vitamin A. However, in the NHANES III study, serum retinol was found to be lower in subjects with elevated CRP concentrations [38].

Others have suggested that the low plasma/serum levels of antioxidants seen in RA patients are a result of an inadequate dietary intake. A number of authors have documented poor intakes of antioxidants among RA patients [34,39-41], but all studies are not in agreement [42]. Furthermore, in all of the studies where the nutrient intake was reported to be deficient, the energy intake was also rather low. Thus, it is not unlikely that the subjects have underreported their dietary intake. In the present study we have primarily related the dietary intake to the AR according to the NNR. When under-reporters were excluded (one MD and two CD subjects) all the subjects reached the AR for vitamin A and C. However, with regard to the selenium intake, $27 \%$ (4/15) of the CD subjects did not reach the AR for selenium. For vitamin $\mathrm{E}$ there is no specified $\mathrm{AR}$, but in comparison with the recommended intake (RI) all of the MD subjects and $60 \%(9 / 15)$ of the CD subjects (excluding under-reporters) reached the RI, which for most people is considerably higher than the requirement. Hence, the result of this study does not point towards an inadequate nutrient intake, perhaps with the exception of selenium. However, our subjects had volunteered to participate in a dietary intervention study and may not have been representative for Swedish RA patients in general. For instance, they might have had a greater interest in 
nutrition, and perhaps their dietary intake was, for this reason, better than the intake of other RA patients.

Since antioxidant-rich foods, such as fruit and vegetables, are in general regarded as healthy, it is possible that the subjects have over-reported their intake of these food items and consequently the nutrient intake would be overestimated as well. If this was the case it could explain the lack of correlation between nutrient intake and the plasma levels of the corresponding nutrient, at least if, for instance, subjects with a low nutrient intake over-report to a greater extent.

Even if the reported intake of food items and nutrients was correct, it may not have been sufficient to substantially raise the plasma levels. In the study on healthy subjects by Zino et al [28], an average extra intake of $700 \mathrm{~g}$ of fruit and vegetables per day resulted in raised levels of plasma antioxidants (vitamin $\mathrm{C}, \alpha$ - and $\beta$-carotene). Regarding vitamin E, McGavin et al showed that an increased intake of vitamin E from, on average, $10 \mathrm{mg} /$ day to $22 \mathrm{mg} /$ day only resulted in a small increase in plasma $\alpha$-tocopherol in healthy subjects [29]. For patients with RA the required amount could be even higher due to the impact of the disease.

In the present study, we have mainly focused on wellknown antioxidant nutrients. However, fruit, vegetables, olive oil and tea also contain phytochemicals, such as phenolic compounds, which in recent years have attracted increased interest $[2,3,13]$. Apart from functioning as antioxidants these compounds have been attributed antiinflammatory, antibiotic, and anti-carcinogenic properties [43]. In a recent study by Halvorsen et al, the total antioxidant capacity of dietary plants was measured by the FRAP assay [44]. They found that the antioxidants vitamin C, $\alpha$-tochopherol, $\alpha$-carotene, $\beta$-carotene, lutein, zeaxanthin and lycopene only contributed to $<25 \%$ of the FRAP values of most dietary plants. Their results suggest that other antioxidants may be of considerable importance for the total antioxidative capacity. However, at this point knowledge about the bio-availability and the in vivo activity of the different phenolic compounds is still insufficient.

\section{Uric acid}

Uric acid is an end product of purine metabolism, which also serves as a water soluble antioxidant and is present in high concentrations in plasma. Situnayake et al [36] investigated the combined chain breaking antioxidant ability of human serum by means of the Total (Peroxyl) Radicaltrapping Antioxidant Parameter (TRAP) assay. They found that serum urate was the most important determinant of TRAP in RA patients. In contrast, in the healthy control group vitamin $\mathrm{E}$ explained most of the variance in TRAP
[36]. However, others have reported that urate also contributed $35-60 \%$ to TRAP in healthy subjects [45]. It is not likely that a shift to a Mediterranean-type diet would lead to an increase in ingested nucleic acids, nor to increased hydrolysis of endogenous nucleic acids and thereby increase the plasma level of uric acid. However, since uric acid contributes to the total antioxidant capacity we decided to investigate the uric acid level as well. There was a tendency to increased levels of uric acid in the MD group at the start of the study, however by week 12 there was no significant difference compared to baseline. The inverse correlation between the thrombocyte count and uric acid indicates that the level of uric acid is associated with the degree of inflammation.

\section{Malondialdehyde}

In rheumatoid joints activated macrophages and neutrophils release several kinds of oxidants, which in high concentrations lead to oxidative stress causing damage to lipids, proteins, carbohydrates and DNA. Important targets for oxidants are the unsaturated fatty acids in cell membranes. MDA is a product of lipid peroxidation and thereby functions as a marker of oxidative stress. The level of MDA in plasma or serum has been reported to be higher in RA patients than in control subjects [46-49]. Earlier studies have also shown that the level of MDA is related to RA disease activity. In one study Taysi et al [49], found that serum MDA correlated positively with disease activity score, and Deaney et al [50], have reported a correlation between ESR and MDA plus another lipid peroxidation product, 4-hydroxynonenal. In the present study, where most patients had low to moderate disease activity, no correlation between urine MDA and disease activity variables were found. On the other hand, $\gamma$-tocopherol was inversely correlated to MDA at baseline. At a group level, no significant changes in MDA or adjusted MDA were seen from baseline to the end of the study, indicating that lipid peroxidation was not significantly affected by the intervention.

\section{Conclusions}

In conclusion, the intake frequencies of antioxidant rich food items were increased in the MD group, and this group also had a significantly higher intake of vitamin $\mathrm{E}$ and selenium compared to the $\mathrm{CD}$ group. Despite the reported increase in consumption frequency of antioxidant-rich foods, the plasma levels of carotenoids, vitamin $\mathrm{C}$, lipid adjusted tocopherols, uric acid and MDA were unchanged by the end of the study. The plasma levels of retinol, vitamin $\mathrm{C}$ and uric acid were, however, correlated to indices of disease activity.

\section{Competing interests}

None declared 


\section{Authors' contributions}

LH participated in the conception, design, data analysis and the writing of the manuscript. PL participated in the data analysis, the critical revision of the manuscript and the writing of parts of the paper. LS participated in the conception, design, data analysis and the critical revision of the manuscript. JA participated in the data analysis and the critical revision of the manuscript. GJ participated in the conception, design, data analysis and the critical revision of the manuscript. All authors have read and approved the last version of the manuscript.

\section{Acknowledgements}

We would like to express our gratitude to our collaborators, Lena Martinsson, Eva Wolke, Ingela Nilsson, Lena Henningsson, Marianne Olsson, AnnLouise Karlsson, Mona Bäckström and Gunnel Gustavsson for administrative assistance, information, advice and support to the patients concerning their diet, help with the clinical examinations, and in the handling of blood and urine samples for chemical analyses.

We would like to thank Maria Bengtsson and Jenny Wannstedt for performing diet history interviews, Petra Rydén for her help with the processing of food questionnaires, and Christel Larsson for valuable discussions regarding the dietary assessments.

We also wish to express our gratitude to all the participants.

The study was supported by grants from the Faculty of Social Sciences of Umeå University, the Swedish Foundation for Health Care Sciences and Allergy Research, the Health Research Council in the Southeast of Sweden, the Swedish Rheumatism Association, the Swedish Nutrition Foundation, the JC Kempe Memorial Scholarship Fund, the "Borgerskapet i Umeå" Fund and the "Uppsala Hemsysterskola" Fund. Olive oil and canola oil, were supplied by Karlshamns $A B$, vegetables by Nestlé Sweden $A B$ and margarine by Van den Bergh Foods AB.

\section{References}

I. Sköldstam L, Hagfors $L$ and Johansson G: An experimental study of a Mediterranean diet intervention for patients with rheumatoid arthritis. Ann Rheum Dis 2003, 62:208-214.

2. Visioli F: Antioxidants in Mediterranean diets. World Rev Nutr Diet 2000, 87:43-55.

3. Trichopoulou A, Vasilopoulou E, Hollman P, Chamalides C, Foufa E, Kaloudis T, Kromhout D, Miskaki P, Petrochilou I, Poulima E, Stafilakis $\mathrm{K}$ and Theophilou $\mathrm{D}$ : Nutritional composition and flavonoid content of edible wild greens and green pies: A potential rich source of antioxidant nutrients in the Mediterranean diet. Food Chem 2000, 70:319-323.

4. Galli C and Visioli F: Antioxidant properties of Mediterranean diet. Int J Vitam Nutr Res 200 I, 7 I:185-188.

5. Trichopoulou A, Naska A and Vasilopoulou E: Guidelines for the intake of vegetables and fruit: the Mediterranean approach. Int J Vitam Nutr Res 200 I, 7 I:149-I53.

6. Heliövaara $M$, Knekt $P$ and Aho R-K: Serum antioxidants and risk of rheumatoid arthritis. Ann Rheum Dis 1994, 53:51-53.

7. Comstock GW, Burke AE, Hoffman SC, Helzlsouer KJ, Bendich A, Masi AT, Norkus EP, Malamet RL and Gershwin ME: Serum concentrations of alpha tocopherol, beta carotene, and retinol preceding the diagnosis of rheumatoid arthritis and systemic lupus erythematosus. Ann Rheum Dis 1997, 56:323-325.

8. Knekt P, Heliovaara M, Aho K, Alfthan G, Marniemi J and Aromaa A: Serum selenium, serum alpha-tocopherol, and the risk of rheumatoid arthritis. Epidemiology 2000, I I:402-405.

9. Bauerova $K$ and Bezek $A$ : Role of reactive oxygen and nitrogen species in etiopathogenesis of rheumatoid arthritis. Gen Physiol Biophys 1999, 18:15-20.
10. Halevy $\mathrm{O}$ and Sklan D: Inhibition of arachidonic acid oxidation by beta-carotene, retinol and alpha-tocopherol. Biochim Biophys Acta 1987, 9 I 8:304-307.

II. Petroni A, Blasevich M, Salami M, Servili M, Montedoro GF and Galli $C$ : A phenolic antioxidant extracted from olive oil inhibits platelet aggregation and arachidonic acid metabolism in vitro. World Rev Nutr Diet 1994, 75: I69-I72.

12. Jiang Q, Elson-Schwab I, Courtemanche $C$ and Ames BN: Gammatocopherol and its major metabolite, in contrast to alphatocopherol, inhibit cyclooxygenase activity in macrophages and epithelial cells. Proc Natl Acad Sci U S A 2000, 97: I I 494-I I 499.

13. Guardia T, Rotelli AE, Juarez AO and Pelzer LE: Anti-inflammatory properties of plant flavonoids. Effects of rutin, quercetin and hesperidin on adjuvant arthritis in rat. Farmaco 200I, 56:683-687.

14. Mangge H, Hermann J and Schauenstein K: Diet and Rheumatoid arthritis - A review. Scand J Rheumatol I999, 28:201-209.

15. Edmonds SE, Winyard PG, Guo R, Kidd B, Merry P, Langrish-Smith A, Hansen C, Ramm S and Blake DR: Putative analgesic activity of repeated oral doses of vitamin $E$ in the treatment of rheumatoid arthritis. Results of a prospective placebo controlled double blind trial. Ann Rheum Dis 1997, 56:649-655.

16. Helmy M, Shohayeb M, Helmy MH and El-Bassiouni EA: Antioxidants as adjuvant therapy in rheumatoid disease. A preliminary study. Arzneimittelforschung 2001, 51:293-298.

17. Arnett FA, Edworthy SM and Bloch DA: The American Rheumatism Association 1987 revised criteria for the classification of rheumatoid arthritis. Arthritis Rheum 1988, 3 I:315-324.

18. de Lorgeril M, Renaud S, Mamelle N, Salen P, Martin J-L, Monjaud I, Guidollet J, Touboul P and Delaye J: Mediterranean alpha-linolenic acid-rich diet in secondary prevention of coronary heart disease. Lancet 1994, 343:1454-|459.

19. Håglin L, Hagman $U$ and Nilsson M: Evaluation of the meal model "Matmallen" A means of estimating consumed amounts of food. Scandinavian Journal of Nutrition 1995, 39:79-83.

20. Swedish National Food Administration: Vikttabell. Uppsala: 1999.

21. Lissner $L$, Lindroos $A K$ and Sjöström L: Swedish obese subjects (SOS): an obesity intervention study with a nutritional perspective. Eur J Clin Nutr 1998, 52:316-322.

22. Black $A E$, Bingham SA, Johansson $G$ and Coward WA: Validation of dietary intakes of protein and energy against 24 hour urinary $\mathbf{N}$ and DLW energy expenditure in middle-aged women, retired men and post-obese subjects: comparisons with validation against presumed energy requirements. Eur J Clin Nutr 1997, 5 1:405-413.

23. Hess D, Keller HE, Oberlin B, Bonfanti R and Schüep W: Simultaneous determination of retinol, tocopherols, carotenes and lycopene in plasma by means of high-performance liquid chromatography on reversed phase. Int J Vitam Nutr Res I99I, 61:232-238.

24. Nordiska ministerrådet: Nordiska näringsrekommendationer 1996. Copenhagen: Nordiska ministerrådet 1996.

25. Sandström B, Lyhne N, Pedersen JI, Aro A, Thorsdóttir I and Becker W: Nordic nutrition rekommendations. Scand J Nutr 1996, 40: $16 \mid-165$

26. Thurnham DI, Davies JA, Crump BJ, Situnayake RD and Davies $M$ : The use of different lipids to express serum tocopherol: lipid ratios for the measurement of vitamin E status. Ann Clin Biochem 1986, 23:5।4-520.

27. Tulleken JE, Limburg PC and Muskiet FAJ: Vitamin E status during dietary fish oil supplementation in rheumatoid arthritis. Arthritis Rheum 1990, 33:1416-1419.

28. Zino S, Skeaff M, Williams S and Mann J: Randomised controlled trial of effect of fruit and vegetable consumption on plasma concentrations of lipids and antioxidants. BMJ 1997, 3 | 4: |787-|79|.

29. McGavin JK, Mann JI, Skeaff CM and Chisholm A: Comparison of a vitamin E-rich diet and supplemental vitamin $E$ on measures of vitamin E status and lipoprotein profile. Eur J Clin Nutr 200I, 55:555-56I.

30. Dore-Duffy P, Peterson M, Catalanotto F, Marlow S, Ho SY, Ostrom $M$ and Weinstein $A$ : Zinc profiles in rheumatoid arthritis. Clin Exp Rheumatol 1990, 8:541-546.

31. Naveh Y, Schapira D, Ravel Y, Geller E and Scharf Y: Zinc metabolism in rheumatoid arthritis: plasma and urinary zinc and relationship to disease activity. J Rheumatol 1997, 24:643-646. 
32. O'Dell JR, Lemley-Gillespie S, Palmer WR, Weaver AL, Moore GF and Klassen LW: Serum selenium concentrations in rheumatoid arthritis. Ann Rheum Dis 1991, 50:376-378.

33. Köse K, Dogan P, Kardas $Y$ and Saraymen R: Plasma selenium levels in rheumatoid arthritis. Biol Trace Elem Res 1996, 53:5I-56.

34. Morgan SL, Andersson AM, Hood SM, Matthews PA, Lee JY and Alarcón GS: Nutrient intake patterns, body mass index, and vitamin levels in patients with rheumatoid arthritis. Arthritis Care Res 1997, 10:9-17.

35. Honkanen V, Konttinen YT and Mussalo-Rauhamaa $\mathrm{H}$ : Vitamins A and $E$, retinol binding protein and zinc in rheumatoid arthritis. Clin Exp Rheumatol 1989, 7:465-469.

36. Situnayake RD, Thurnham DI, Kootathep S, Chirico S, Lunec J, Davis $M$ and McConkey $B$ : Chain breaking antioxidant status in rheumatoid arthritis: clinical and laboratory correlates. Ann Rheum Dis 1991, 50:81-86.

37. Honkanen V, Konttinen YT, Sorsa T, Hukkanen M, Kemppinen P, Santavirta S, Saari H and Westermarck T: Serum zinc, copper and selenium in rheumatoid arthritis. J Trace Elem Electrolytes Health Dis |99|, 5:26|-263.

38. Stephensen $C B$ and Gildengorin G: Serum retinol, the acute phase response, and the apparent misclassification of vitamin A status in the third National Health and Nutrition Examination Survey. Am J Clin Nutr 2000, 72: I I70- I I78.

39. Kremer JM and Bigaouette J: Nutrient intake of patients with rheumatoid arthritis is deficient in pyridoxine, zinc, copper, and magnesium. J Rheumatol 1996, 23:990-994.

40. Kowsari B, Finnie SK, Carter RL, Love J, Katz P, Longley S and Panush RS: Assessment of the diet of patients with rheumatoid arthritis and osteoarthritis. J Am Diet Assoc 1983, 82:657-659.

4I. Stone J, Doube A, Dudson D and Wallace J: Inadequate calcium folic acid, vitamin $E$, zinc, and selenium intake in rheumatoid arthritis patients: results of a dietary survey. Semin Arthritis Rheum 1997, 27:180-185.

42. Honkanen VE, Lamberg-Allardt $\mathrm{CH}$, Vesterinen MK, Lehto JH, Westermarck TW, Metsa-Ketela TK, Mussalo-Rauhamaa MH and Konttinen YT: Plasma zinc and copper concentrations in rheumatoid arthritis: influence of dietary factors and disease activity. Am J Clin Nutr 1991, 54:1082-1086.

43. Bravo L: Polyphenols: chemistry, dietary sources, metabolism, and nutritional significance. Nutr Rev 1998, 56:3 I7-333.

44. Halvorsen BL, Hotle K, Myhrstad MCW, Barikmo I, Hvattum E, Fagertun Remberg S, Wold A-B, Haffner K, Baugerod H, Andersen LF, Moskaug JO, Jacobs DR and Blomhoff R: A systematic screening of total antioxidants in dietary plants. I Nutr 2002, | 32:46 I-47|

45. Wayner DD, Burton GW, Ingold KU, Barclay LR and Locke SJ: The relative contributions of vitamin $E$, urate, ascorbate and proteins to the total peroxyl radical-trapping antioxidant activity of human blood plasma. Biochim Biophys Acta 1987, 924:408-419.

46. Gambhir JK, Lali P and Jain AK: Correlation between blood antioxidant levels and lipid peroxidation in rheumatoid arthritis. Clin Biochem 1997, 30:351-355.

47. Özgünes $\mathrm{H}$, Gürer $\mathrm{H}$ and Tuncer S: Correlation between plasma malondialdehyde and ceruloplasmin activity values in rheumatoid arthritis. Clin Biochem 1995, 28:193-194.

48. Öztürk HS, Cimen MY, Cimen OB, Kacmaz M and Durak I: Oxidant/ antioxidant status of plasma samples from patients with rheumatoid arthritis. Rheumatol Int 1999, 19:35-37.

49. Taysi S, Polat F, Gul M, Sari RA and Bakan E: Lipid peroxidation, some extracellular antioxidants, and antioxidant enzymes in serum of patients with rheumatoid arthritis. Rheumatol Int 2002, 2 I:200-204.

50. Deaney CL, Feyi K, Forrest CM, Freeman A, Harman G, McDonald MS, Petrie A, Shaw SJ, Stone TW, Stoy N and Darlington LG: Levels of lipid peroxidation products in a chronic inflammatory disorder. Res Commun Mol Pathol Pharmacol 200 I, I I 0:87-95.

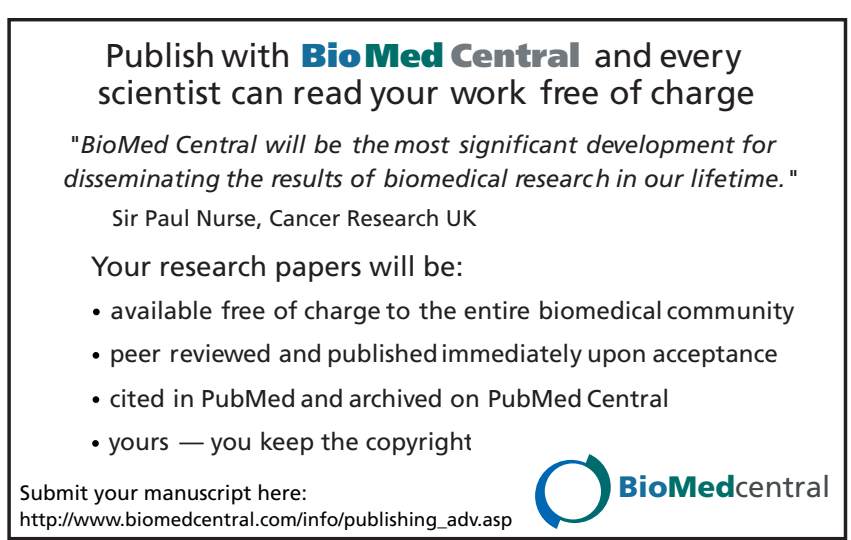

